\title{
New hatchery methods for efficient spore use and seedling production of Palmaria palmata (dulse)
}

\section{Schmedes, Peter Søndergaard; Nielsen, Mette Møller}

\section{Published in:}

Journal of Applied Phycology

Link to article, DOI:

$10.1007 / \mathrm{s} 10811-019-01998-0$

Publication date:

2020

Document Version

Peer reviewed version

Link back to DTU Orbit

Citation (APA):

Schmedes, P. S., \& Nielsen, M. M. (2020). New hatchery methods for efficient spore use and seedling production of Palmaria palmata (dulse). Journal of Applied Phycology, 32, 2183-2193.

https://doi.org/10.1007/s10811-019-01998-0

\section{General rights}

Copyright and moral rights for the publications made accessible in the public portal are retained by the authors and/or other copyright owners and it is a condition of accessing publications that users recognise and abide by the legal requirements associated with these rights.

- Users may download and print one copy of any publication from the public portal for the purpose of private study or research.

- You may not further distribute the material or use it for any profit-making activity or commercial gain

- You may freely distribute the URL identifying the publication in the public portal 
New hatchery methods for efficient spore use and seedling production of Palmaria palmata (dulse)

\section{Abstract \\ Abstract}

Peter Søndergaard Schmedes $1, a$, Mette Møller Nielsen¹

${ }^{1}$ Technical University of Denmark, DTU Aqua, Øroddevej 80, 7900 Nykøbing Mors, Denmark https://orcid.org/0000-0001-5772-4737

Key words: Dispersal, fertilization, hatchery, tetraspores, reattachment, spore seeding

aCorresponding author: peson@aqua.dtu.dk

Palmaria palmata (dulse) is a high valued rhodophyte; nevertheless, its hatchery methods are underdeveloped. New hatchery methods are required to improve the spore use efficiency and seeding quality, which are important benchmarks for a viable cultivation. This study investigated a method using vertical seeding tanks (exp. 1), hemispherical agitation and flow-through conditions to improve spore dispersal on net substrates. Tanks were inoculated with different amounts of sori tissue, which sporulated in three consecutive seeding periods. The results demonstrated significant effect of seeding period where 5-15 g FW sori could be used to seed three nets ( 126 m rope) over the course of nine days providing a density up to 10 seedlings $\mathrm{cm}^{-1}$ after 32 days. The effluent spores were collected in detaining tanks and germinated into a propagule mix of female and male gametophytes. The propagule mix was efficient as a secondary seeding inoculum, as propagules were able to reattach to substrates up to 39 days after their release as spores (exp.2). Adding male gametes to the propagule mix and spore seeded ropes was tested as a relevant hatchery step to activate female gametophytes and significantly resulted in more than a doubling of seedlings (exp.3). This study present new methods and strategies to improve spore use efficiency and to obtain an equal spore dispersal on net substrates for hatchery production of $P$. palmata. 
1. Introduction

The rhodophyte Palmaria palmata (L.) F. Weber and D. Mohr has traditionally been used for human consumption with records dating back to the $9^{\text {th }}$ century (Mouritsen et al. 2013). The emerging evidence of its umami flavor (Mouritsen et al. 2013), bioactive and health properties of protein hydrolysates (Harnedy et al. 2014; Admassu et al. 2018), water extracts (Lee et al. 2017) and biorefined compounds (Schiener et al. 2017) has renewed interest in the use of $P$. palmata, resulting in increased focus on its cultivation. $P$. palmata can be cultivated in tanks using vegetative growth (Morgan and Simpson 1981; Pang and Lüning 2004; Matos et al. 2006; Corey et al. 2014), but the prospects of cultivating the species from tetraspores has lately received increasing attention in Europe (Edwards and Dring 2011; Werner and Dring 2011; Sanderson et al. 2012). However, despite studies founding the essential understanding of the life cycle (van der Meer and Chen 1979; van der Meer and Todd 1980) and cultivating P. palmata from spores (Browne 2001; Sanderson 2006; Werner and Dring 2011; Grandorf Bak 2019; Schmedes et al. 2019), the methodology for large-scale hatchery production in Europe is still in its infancy.

Essentially, the use of spores for cultivation of $P$. palmata is based on three steps; 1 ) the collection or induction of sori, 2) the release and dispersal of spores and 3) the spore attachment and growth; and it is the efficiency and success of these three steps that determines the usefulness of a given hatchery protocol. As the steps are interlinked, the initial handling of sori, which represent only $8-10 \%$ of the total frond area during the peak season of fertility (Werner and Dring 2011), is crucially important. Currently, the most commonly used hatchery protocol to produce $P$. palmata seeded substrates is a flat tank using a 1:1 areal coverage of substrate with sori and a three days spore release duration. However, this method requires a large amount of sori, and furthermore, results in poor dispersal and high mortality (60-90\%) of the spores (Werner and Dring 2011). Also, by the using this method, it is often observed that a considerable amount of the spores settle on tank surfaces instead of the intended cultivation substrate (personal observation).

Taking into account these results and observations, it is clear that there is a bottleneck in spore use efficiency within $P$. palmata hatcheries. This particular matter was addressed in a recent study suggesting a GMA-seeding method (Germination, Maceration, and Agitation method) as an alternative seeding method for P. palmata (Schmedes et al. 2019). This study found that germinated propagules (i.e. a mix of spores and seedlings) of $P$. palmata were able to establish discoid reattachment to a substrate after forced deattachment and maceration, resulting in high settlement efficiency as well as a high dispersal of the propagules. However, the extensive use of this seeding method is still unknown. Besides the use of this seeding strategy, the use of male gametes of $P$. palmata to fertilize female gametophytes has been suggested as a potential hatchery step to optimize the hatchery production (Mine and Tatewaki 1994; Le Gall et al. 2004; Schmedes et al. 2019). When using sori for spore-seeding, a mixture of male and female spores develop after attachment, however, only the males will develop into a harvestable thallus unless a fertilization step, enabling zygote formation in the female gametophyte, is included. Theoretically, this would double the seedling density, as the crustose-like female gametophyte will develop into a sporophytic thallus after the zygote. Yet, this is still uninvestigated under relevant hatchery conditions. Because of the continued challenges in producing P. palmata sporophytes and gametophytes, this present study investigated hatchery methods and strategies based on Schmedes et al. (2019) to further improve the 
utilization of spores for cultivation of $P$. palmata on substrates. Five strategies to improve the hatchery protocol were tested: 1) A vertical seeding tank in flow-through condition agitated with air bubbles to promote dispersal of spores. 2) The effect of different amount of sori during the seeding phase. 3) The effect of using the same sori material in three consecutive seeding periods on the spore germination and seedling density. 4) The use of detained spores as a propagule seeding inoculum, based on the GMA-method. 5) The effect of fertilization on the number of attached seedlings under relevant hatchery conditions.

\section{Materials and methods}

Three experiments were set up to test the five improvements in hatchery techniques described above. Experiment 1 investigated a new flow-through seeding system for improved seeding dispersal, additionally using different sori amounts in consecutive seeding periods as a means to improve sori use. This experiment addressed the first three steps of hatchery improvements. Experiment 2 covered step four, optimizing the use of detained spores, and finally, experiment 3 exploited the opportunity to include fertilization as a means to improve spore use, addressing step five of hatchery improvement techniques.

\subsection{Experiment 1: spore seeding and sori use.}

Nine conical tanks (polyethylene, $30 \mathrm{~L}$ ) were set up as seeding tanks in a parallel flow-through system with a water flow of $0.5 \mathrm{~L} \mathrm{~min}^{-1}$ (fig. $1 \mathrm{~A}$ ) in a $10^{\circ} \mathrm{C}$ cold room. Air bubbles from the bottom (1.2 $\mathrm{L} \mathrm{min}^{-1}$ ) bubbled through the sori package near the surface (fig. 1C), generated a hemispherical circulation of the water allowing the spores to disperse and aerated the tank volume. Water for the entire system was circulated from a reservoir tank with a circulation pump and exchanged (10\% of total volume) on a daily basis. No nutrients were added. From each seeding tank, an outlet, placed diagonal to the inlet, led the effluent water directly into a 2 L spore-detaining tank (SDT) (fig. 1B). Here, effluent spores aggregated on the bottom, while water was led out in the top and back to the reservoir tank through a nylon filter $(15 \mu \mathrm{m})$ for UV treatment $(60 \mathrm{~W})$. Spores detained in the SDTs were used in experiment 2.

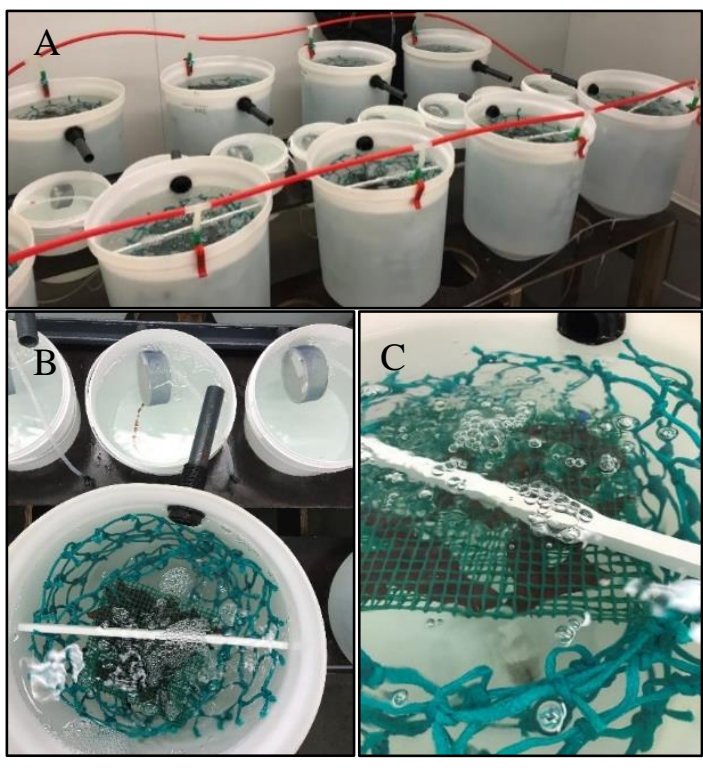

Figure 1. 
Twenty-seven pieces of net (polypropylene, $0.25 * 1.40 \mathrm{~m}, \varnothing=5-7 \mathrm{~mm}$ ) were prepared as cultivation substrate by soaking them in lukewarm tap water a month before, then kept in clean seawater for seven days before use. At the experimental start, the nets were submerged in the seeding tanks as a two-layered net spiral (fig. 1B).

Fertile P. palmata tetrasporophytes and male gametophytes were collected 4 January 2019 in the intertidal zone near Fornæs light house, Denmark (56.443534N, 10.958985E) and kept in running seawater $\left(4^{\circ} \mathrm{C}\right)$ in dim natural light ( $15 \mu \mathrm{mol}$ photons $\mathrm{m}^{-2} \mathrm{~s}^{-1}$, PAR). On 10 January, 218 fertile fronds were rinsed in $0.2 \mu \mathrm{m}$ filtered and sterilized seawater (fig. $2 \mathrm{~A}$ ) before being desiccated for 20 hours at $5{ }^{\circ} \mathrm{C}$ in darkness. Presence of ripe sporangia was verified by inspection (fig. 2B). Triplicates of three groups of sori amount $(5,10$ or $15 \mathrm{~g}$ FW; fresh weight) were prepared as sori packages by placing the tissue between two layers of plastic net $\left(15^{\star} 15 \mathrm{~cm}\right.$, fig. $\left.2 \mathrm{C}\right)$.

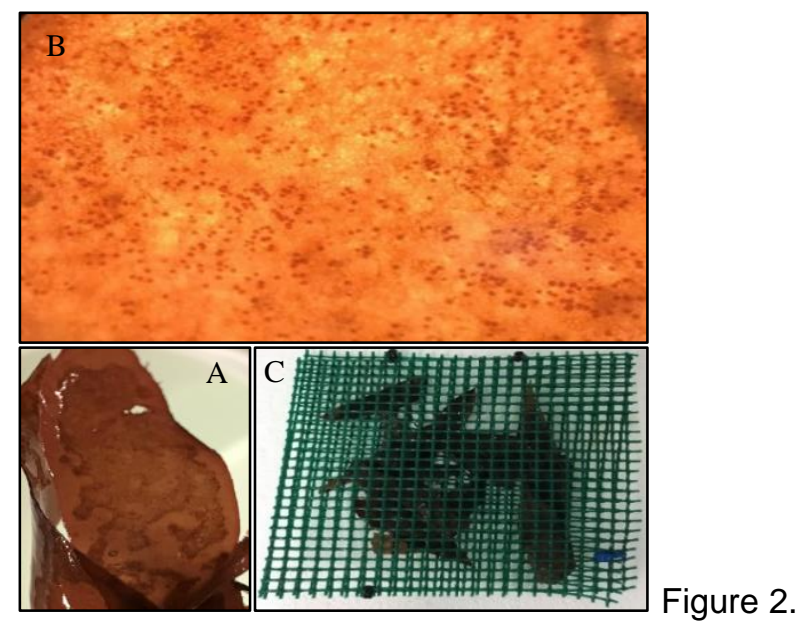

The experiment started $11^{\text {th }}$ of January 2019 by adding a net and a sori package ( 3 replicates of 3 sori amounts) to each of the nine tanks. The seeding ran over a course of nine days, keeping the same sori package in the tanks for all nine days but exchanging the nets with new ones every third day to test the potential of consecutive seeding periods (Day 0-3, Day 3-6, Day 6-9) using the same sori. During seeding, the surface irradiance was 15-22 $\mu \mathrm{mol}$ photons $\mathrm{m}^{-2} \mathrm{~s}^{-1}, 10: 14 \mathrm{~h} \mathrm{~L}$ : $\mathrm{D}$. At the end of each consecutive seeding period, the nine nets were labelled and transferred to nursery tanks containing $300 \mathrm{~L}$ enriched seawater $(0.2$ $\mu \mathrm{m}$ filtered); $10 \%$ strength of Varicon Aqua Cell-Hi F2P, a F/2 nutrient media with vitamins based on Guillard and Ryther (1962). Air stones provided water agitation in the tanks after three days. Irradiance was $35 \mu \mathrm{mol}$ photons $\mathrm{m}^{-2} \mathrm{~s}^{-1}(10: 14 \mathrm{~h} \mathrm{~L}: \mathrm{D})$, but raised to $50 \mu \mathrm{mol}$ photons $\mathrm{m}^{-2} \mathrm{~s}^{-1}$ from week 2 .

\section{Data acquisition}

The net-seeding efficiency using sori in the flow-through system was calculated by equation 1 :

$$
\text { Net seeding efficiency }=\frac{\# \text { spores on net }}{\# \text { Total spores }(\text { net }+ \text { detained })} * 100 \%
$$


This was carried out by counting the number of attached spores and seedlings on a $4 \mathrm{~cm}$ net subsample for each of the 9 nets $(n=3)$ three days after each seeding period. Additionally, the nets were counted at day 19 and 32 after each of the consecutive seeding periods to compare spore and seedling density within and between groups over time. The subsamples were taken from the same position regarding the in, - and outlet of the tanks on each net spiral. To verify an even spore dispersal on the entire net, additional subsamples were taken from the $10 \mathrm{~g}$ sori batch in the first seeding period (Day $0-3)$. From each net $(n=3)$, three subsamples were taken from the bottom and top part of the net $(\mathrm{N}=9)$ and tested for unequal variance using Levene's test. Similarly, by counting spores on subsamples $(\mathrm{N}=21)$ from all around one net spiral in the same vertical level the spore dispersal was assessed. By verification, we extrapolated the spore and seedling densities for each counting day and calculated the germination success by equation 2 :

$$
\text { Germination }(\%)=\frac{\# \text { Seedlings }}{\# \text { Total propagules (spores }+ \text { seedlings) }} * 100 \%
$$

The total number of detained spores in each SDT after a seeding event (fig. 3A) was estimated based on subsample counting, by the following process: 1) A homogenous spore mix (fig. 3B) was prepared by reducing the SDT volume, dislodging the spore aggregates and macerating the solution for 30 seconds with a kitchen blender. 2) A $10 \mathrm{~mL}$ subsample was transferred to a gridded petri dishes (fig. 3C) and added 20 $\mathrm{mL}$ enriched $(10 \% \mathrm{~F} / 2)$ seawater. 3$)$ The spores were kept at $5{ }^{\circ} \mathrm{C}$ and $5 \pm 2 \mu \mathrm{mol}$ photons $\mathrm{m}^{-2} \mathrm{~s}^{-1}(10: 14 \mathrm{~h}$ $\mathrm{L}: D$ ) for three days before five random fields (each $0.0035 \mathrm{~mm}^{2}$ ) were photographed and counted. The total number of spores was estimated by factor multiplying the mean count of subsamples (STDVoLUME ${ }^{*} 10 \mathrm{~mL}^{-1}$ subsample and petri dish area*0.0035 $\mathrm{mm}^{-2}$ ).

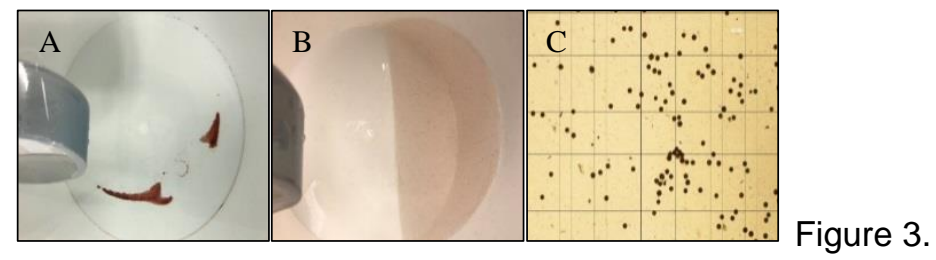

\subsection{Experiment 2: Mixed propagules as seeding inoculum}

In Experiment 2, the propagules germinated from detained spores from experiment 1 were tested as seeding inoculum, according to the GMA-method (Schmedes et al. 2019). After subsampling for petri dish cultures in experiment 1, the rest of the macerated spore solution from the last seeding period (Day 6-9) was poured into a plexiglas containers ( $5 \mathrm{~L}$ ), settled on the bottom (fig. $4 \mathrm{~A}$ ) and cultivated at $20 \mu \mathrm{mol}$ photons $\mathrm{m}^{-2} \mathrm{~s}^{-1}$ (adjusted to $5 \pm 2 \mu \mathrm{mol}$ photons $\mathrm{m}^{-2} \mathrm{~s}^{-1}$, after ten days) and $5^{\circ} \mathrm{C}$. After one day, enriched seawater and germanium-oxide $\left(10 \% \mathrm{~F} / 2+1 \mathrm{mg} \mathrm{L}^{-1} \mathrm{GeO}\right)$ was added and after six days, an air stone was put for aeration. The detained spores germinated into a mixture of propagules (i.e. spores and gametophytes) at these conditions before use.

Twenty-seven days after the initiation of Day 6-9 seeding period, some of the propagules on the bottom were dislodged (Fig. 4B), suspended in $400 \mathrm{~mL}$ enriched (10\% F/2) seawater and macerated to break propagule 
aggregates (fig. 4C) according to Schmedes et al. (2019). The propagules were photographed before and after the maceration treatment (fig. 4D, E). A total of $20 \mathrm{~mL}$ of the propagule mix was added to each of 10 beakers $(n=10)$ containing $400 \mathrm{~mL}$ enriched $(10 \% \mathrm{~F} / 2)$ seawater and a piece of rope $(10 \mathrm{~cm})$ standing upright in the beaker to test the ability of the propagules to reattach. The rope was made by untangling several net meshes and cut and cut into pieces. Immediately, $1 \mathrm{~mL}$ subsamples were withdrawn and the concentration of macerated propagules was estimated to $259 \pm 8$ spores $\mathrm{mL}^{-1}$ and $422 \pm 13$ seedlings $\mathrm{mL}^{-1}$ (mean $\pm S E, n=4)$. The beakers were constantly agitated from the bottom via air bubbles $\left(2.5 \mathrm{~L} \mathrm{~min}^{-1}\right)$ to promote the dispersal of the propagules.
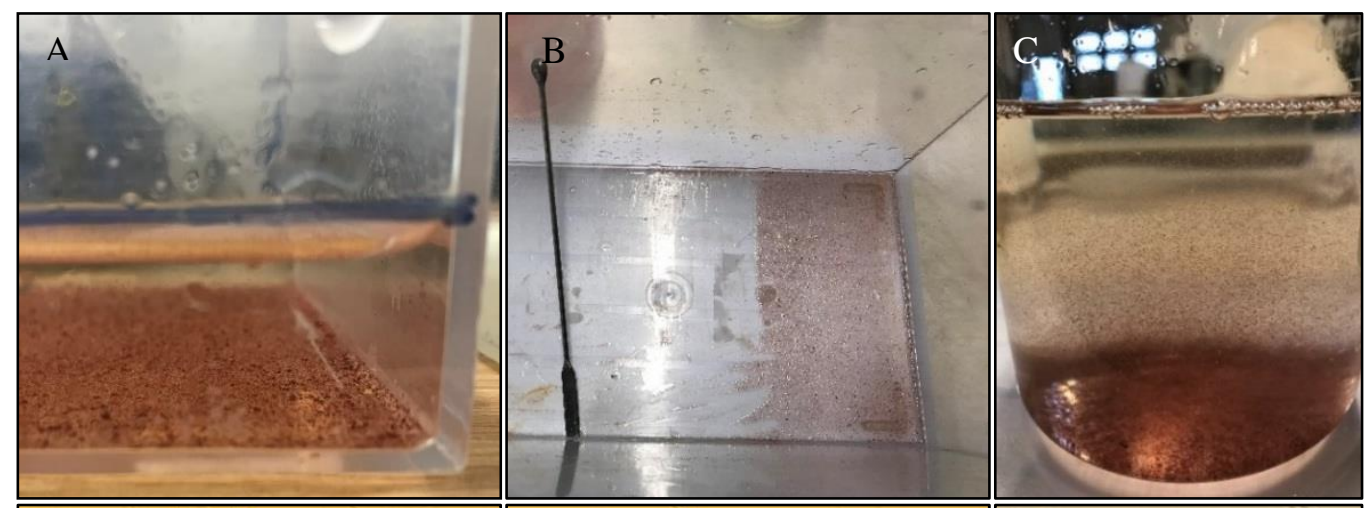

$\mathrm{D}$

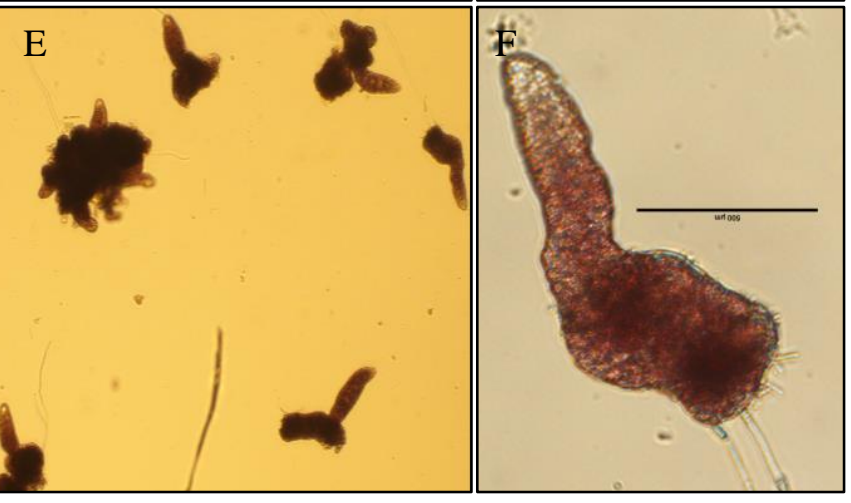

Figure 4.

After 3 days inoculation ("agitation period day0-2"), the maximum density of attached spores and seedlings was estimated by counting the three densest subparts $(0.5 \mathrm{~cm})$ for each rope, after which the ropes were transferred to $20 \mathrm{~L}$ tanks at the similar conditions until they were counted again at day 10 . After transferring the ropes pieces out of the beakers, the propagule mix that maintained in the beakers under same conditions until day 10 , where concentration (mean of technical replicate \pm SE) of spores $(237 \pm 7$ ) and seedlings (394 \pm 9 ) seedlings was similar to the starting concentration (two-sampled t-tests: $t(4), p=0.086, p=0.131$, respectively). Then, new pieces of rope were added for 3 days inoculation to see how long after the dislodgement and maceration the propagules would be able to reattach ("agitation period day10-12"). Also, at day 10 , new beakers $(n=10)$ were set up under same conditions using freshly dislodged and macerated propagules to see if the age of the propagules ( $27 \mathrm{vs.} 37$ days) at dislodgement affected the ability to reattach. The concentration of propagules $(250 \pm 20$ spores and $396 \pm 22$ seedlings) was similar (two-sampled t-tests: $\mathrm{t}(4): p=0.584, p=0.341$ ) with the other start concentrations. 
171 The effect of fertilizing female gametophytes was tested by adding male gametes to propagules cultured in petri dishes and spore-seeded ropes cultured in beakers. A solution of propagules (349 \pm 26 propagules $\mathrm{mL}^{-1}$, $\mathrm{n}=9$, technical replicates) was prepared from the same detained spore batch as used in experiment 2 by dislodging and macerating after 11 days of germination. A total of $15 \mathrm{~mL}$ propagule solution was then poured into each of 18 petri dishes and filled with additional $10 \mathrm{~mL}$ enriched $(10 \% \mathrm{~F} / 2)$ seawater and kept in $15 \pm 3$ $\mu$ mol photons $\mathrm{m}^{-2} \mathrm{~s}^{-1}$ PAR (12:12 $\left.\mathrm{h} \mathrm{L:D}\right)$ irradiance at $5^{\circ} \mathrm{C}$. At day 1 , a solution of male gametes was prepared and $15 \mathrm{~mL}$ of this solution was added to nine petri dishes, containing the propagule solution. Nine other dishes received $15 \mathrm{~mL}$ seawater (10\% F/2) as a control. The male gamete solution was prepared by desiccating $\left(3 \mathrm{~h}\right.$, dark at $\left.5^{\circ} \mathrm{C}\right)$ thirty fertile male gametophytic fronds (22.4 g FW, see fig. $5 \mathrm{~A}$ and $5 \mathrm{~B}$ ) before being rehydrated ( $1 \mathrm{~h}, 5 \mu \mathrm{mol}$ photons $\mathrm{m}^{-2} \mathrm{~s}^{-1}$ PAR) in an agitated volume of $400 \mathrm{~mL}$ seawater $+0.4 \mathrm{~mL} \mathrm{GeO}(1 \mathrm{~g} / \mathrm{L})$. The male gametes $(\varnothing \sim 5 \mu \mathrm{m})$ were visible using high magnification (fig. $5 \mathrm{C}$ and $5 \mathrm{D}$ ). The concentration of gametes was estimated to be $\sim 1000$ gametes $\mathrm{mL}^{-1}$, using a Neubauer cell counting chamber. After adding, the cultures were mixed on a stirring table for $30 \mathrm{~min}$ at $160 \mathrm{rpm}$. At day 4 and 6 , the petri dish volumes were exchanged with new additions of male gamete solution ( $5 \mathrm{~mL}, \sim 10^{6}$ gametes $\left.\mathrm{mL}^{-1}\right)$. For each petri dish, spores and seedlings were counted in five random fields (each $0.0035 \mathrm{~mm}^{2}$ ) at day 0,3 , 10 and 19 and the number of seedlings were adjusted to the spore count of previous counting day.

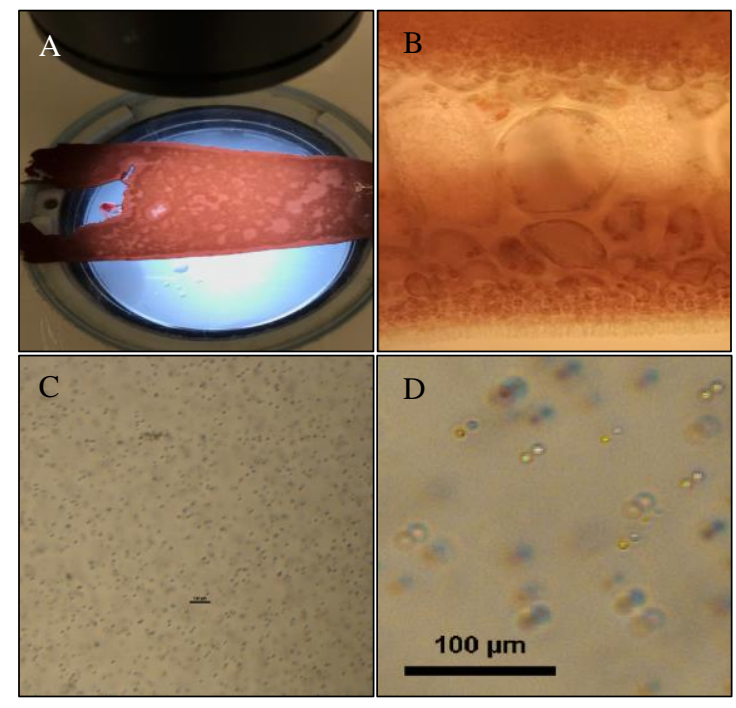

Figure 5.

In addition, we assessed the effect of fertilization on the seeded rope pieces (Exp. 2). This was carried out in beakers $(1.8 \mathrm{~L})$ kept at $5{ }^{\circ} \mathrm{C}$, in which $4 \mathrm{~cm}$ pieces of seeded rope were tumbled by air bubble agitation $(n=11)$. The pieces were excised from "Day 3-6 and $10 \mathrm{~g}$ sori" nets (Exp. 1) and nursed for 16 days at $10^{\circ} \mathrm{C}$, before being transferred to the beakers. This was followed by adding $40 \mathrm{~mL}$ solution containing male gametes to the beakers, while a control group was added the same enriched seawater (10\% F/2) with no gametes $(n=11)$. The numbers of spores and seedlings was counted at day $1,3,6$, and 12 and the seedling number was presented as relative to spore number. 
197 For all data sets, Shapiro Wilks test was used to check normality and Levene test was used to check variance homogeneity. The analysis was carried out using SAS, JMP 13, using a significance level of 0.05 .

199 When sufficient, data were log-transformed to ensure homogeneity of variance and normal distributed 200 residuals and ANOVAs were conducted to compare the main effects. In case of none normal distribution or homogeneity of variance, the Wilcoxon two-sample test was used. All data are given as mean \pm standard error (SE), unless stated otherwise.

Experiment 1. In a factorial design, nets were manipulated to be in one of nine groups forming the combination of consecutive seeding periods (3 levels; Day 0-3, Day 3-6, Day 6-9) and sori amount (3 levels; 5, 10, $15 \mathrm{~g} \mathrm{FW}$ ), and 2-way ANOVA (2w-an), including the interaction term, using log-transformed data was conducted to compare effects on spore and seedling numbers attached to the nets, the number of detained spores in STDs, the spore-seeding efficiency as well as the germination success (\%) between all groups, followed by Tukey's HSD post hoc test. The Wilcoxon two-sample test was used to assess for any significant change in mean densities of spores and seedlings across the counting days within each factorial group.

Experiment 2. Datasets were log-transformed to ensure normal distribution, but spore counts did not obey homogeneity of variance (Levene, $p<0.0208$ ). Hence, the Wilcoxon test was used to assess for significant difference in mean settlement density at each count day.

Experiment 3. For the petri dish cultures, the effect of adding male gametes on the number of seedlings adjusted to the previous spore count was compared using a two-tailed Student's $t$ test $(n=11)$. For the rope cultures, the univariate repeated measures ANOVA was used to test effect of the between factor (two levels; male gametes vs. control) and the within factors (time; four levels) on the adjusted number of seedlings. Datasets were normal distributed and displayed equal variance after log-transformation. The Mauchly's sphericity test: $\chi^{2}(5)=8.3513, p=0.1379$ allowed to report the $p$-value of the $F$ test.

\section{Results}

\subsection{Experiment 1: spore seeding and sori use}

Spores settled on all nets during the consecutive seeding periods and for all amount of sori used (fig. 6A-C). Spores were present on all counting days, while seedlings (fig. 6D-F) were only present from counting day 19 and onwards. On counting day 3 , the number of spores attached to the nets was significantly affected by seeding periods ( $2 \mathrm{w}$-an: $\mathrm{F}_{2,8}=7.2461, p=0.0049$ ), the second (fig. $6 \mathrm{~B}$ ) and third (fig. $6 . \mathrm{C}$ ) seeding period (day 3-6 and day 6-9) showing similar and significant higher spore densities (Tukey's: $p=0.0036$ ) than the first seeding period (day 0-3) (fig. 6A). Also, the sori amount used for seeding, significantly affected the number of attached spores ( $2 \mathrm{w}$-an: $\mathrm{F}_{2,8}=4.0989, p=0.0341$ ), showing significant difference between high and low sori amounts (Tukey's, $p=0.0109$ ). On counting day 19, the number of spores (fig. 6A-C) and seedlings (fig. 6D-F) as well as the spore germination success (fig. $6 \mathrm{G}-\mathrm{I}$ ) was similar for all groups (2w-an: $p>0.5606)$. On counting day 32 , the spore settlement was still similar across all groups ( $2 w$-an: $p>0.1179)$ 
(fig. $6 \mathrm{~A}-\mathrm{C}$ ), whereas the number of seedlings (fig. $6 \mathrm{D}-\mathrm{F}$ ) was significant affected by seeding period ( $2 \mathrm{w}$-an: $F_{2,8}=6.1718, p=0.0091$ ), showing similar seedling density in second and third period (Tukey's, $p=0.8110$ ), both significantly higher than the first seeding period (Tukey's, $p=0.0105, p=0.0383$, respectively). At day 32 , the average seedling density was $36 \pm 8$ seedlings per $4 \mathrm{~cm}$. However, the germination success (fig. $6 \mathrm{G}-\mathrm{I}$ ) up to $50-80 \%$ turned out to be similar between seeding periods ( $2 w$-an: $F_{2,8}=3.0829, p=0.0706$ ) and sori groups ( $2 \mathrm{w}$-an: $\mathrm{F}_{2,8}=0.1873, p=0.83$ ). Within each seeding period (fig. $6 \mathrm{~A}-\mathrm{C}$ ), the spore count decreased significantly over time (Chi-squared: $\chi^{2}(9)=10.14, p=0.0063$ ), whereas the increase in seedling density was only significantly on nets produced in second (Mann-Whitney two-sample test: $p=0.0030)$ and third ( $p=$ 0.0295) seeding periods.

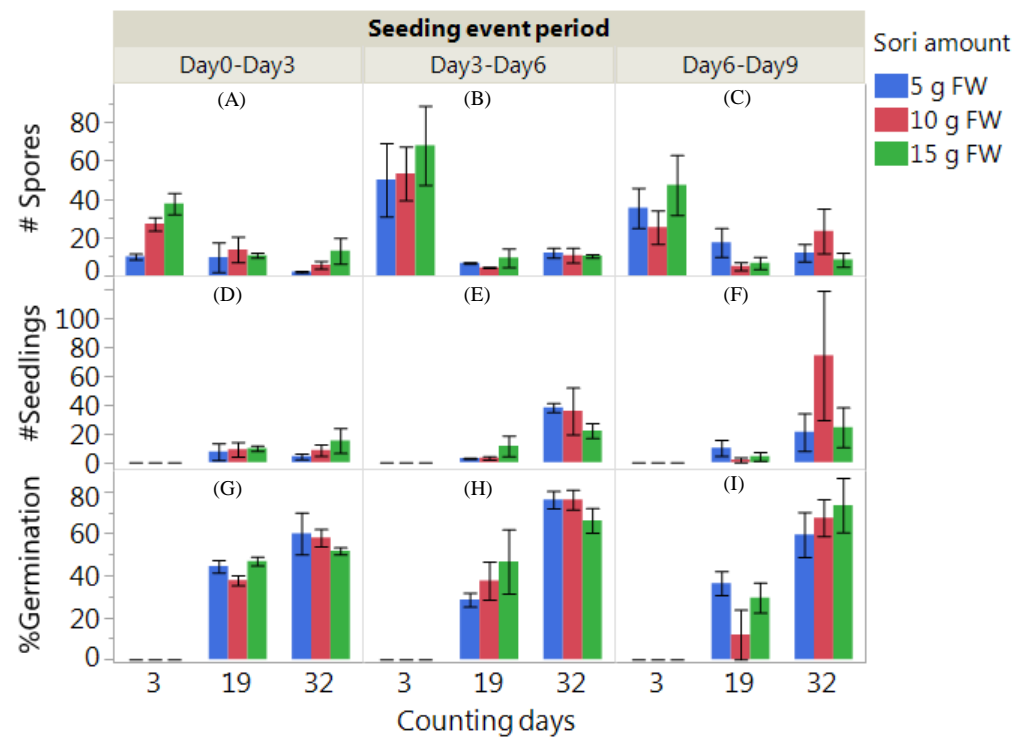

Figure 6.

The additional rope pieces sampled to assess whether settlement was homogeneous dispersed across the entire net, showed that this was the case. Both spores and seedlings showed equal variance between top and bottom of the nets (spores: $p=0.17$, seedlings: $p=0.40$ ) and means (Mann-Whitney two-sample test: $p$ $=0.40$ ). Furthermore, the densities showed equal variance horizontally around the net spiral (spores: $p=$ 0.23 , seedlings: $p=0.33$ ). Hence, the number of spores settled on rope pieces cut from the nets was extrapolated to whole nets (fig. 7A-C) and summed with the number of detained spores (fig. 7D-F) to calculate the total number of released spores. This number was then used to estimate a net seeding efficiency of the system (fig. 7G-I) by equation 1 . The net seeding efficiency of the agitated, flow-through seeding tank system using sori packages was in average $16 \pm 1.6 \%$ (fig.7G-I) and not affected by either seeding period or sori amount ( $2 \mathrm{w}$-an: $p>0.28$ ). This indicates that app. $84 \%$ of the released tetraspores were washed out and detained (fig. 7D-F).

Effluent spores aggregated as red plumages on the bottom of all the SDTs, and were visible within 3 hours during the first seeding period (Day 0-3). The number of detained spores from the flow-through system (fig. $7 D-F$ ) was significantly affected by seeding period ( $2 \mathrm{w}$-an: $\mathrm{F}_{2,8}=5.66, p=0.0124$ ), where second period provided higher detained spore yield compared to the third period (Tukey's: $p=0.0117$ ) and similar spore yield as first period ( $p=0.6593$ ). The amount of sori used also affected the number of detained spores 
significantly ( $2 \mathrm{w}$-an: $\left.\mathrm{F}_{2,8}=5.07, p=0.0178\right)$ where $15 \mathrm{~g}$ sori provided higher yield compared to $5 \mathrm{~g}$ sori

260 (Tukey's: $p=0.0175$ ). In total, the amount of released spores (detained + attached to nets) from the three 261 different sori packages during nine days of sporulation was significantly higher for the $15 \mathrm{~g}$ sori group $262(1,300,563 \pm 71,639)$, compared to the $10 \mathrm{~g}$ sori $(959,697 \pm 69,618)$ and the $5 \mathrm{~g}$ sori group $(522,230 \pm 61,869)$ 263 spores.

264

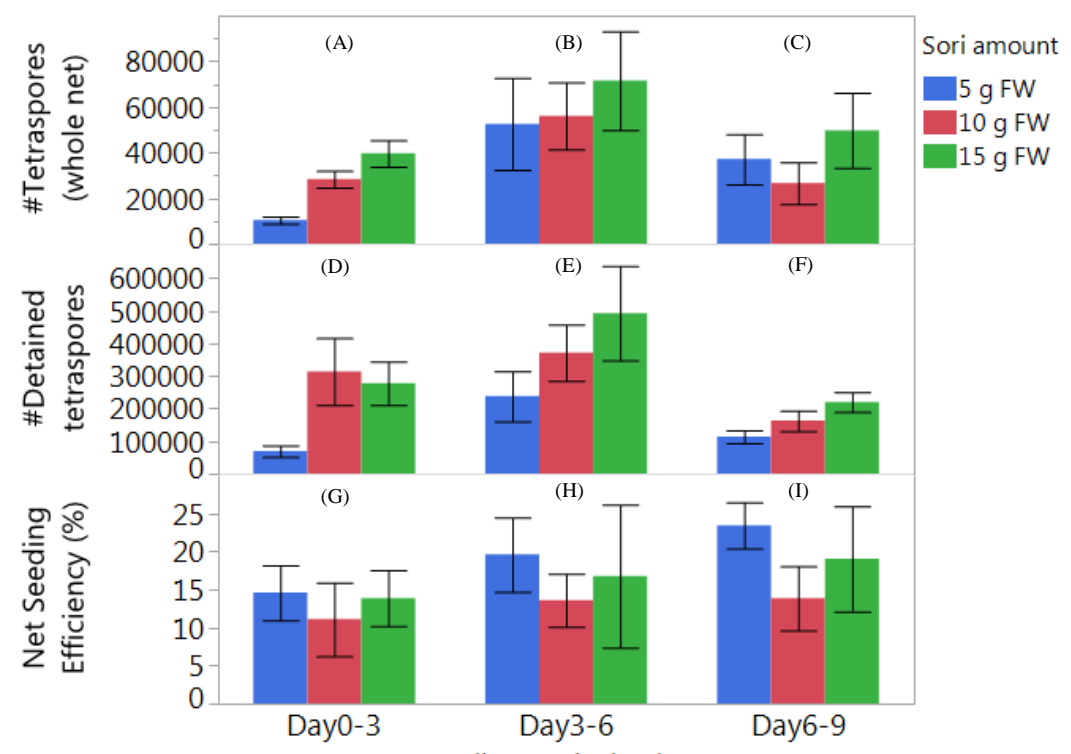

3.2. Experiment 2: Mixed propagules as seeding inoculum

On counting day 3 , the number of reattached spores (fig. $8 \mathrm{~A}$ vs. $8 \mathrm{~B}$ ) and seedlings (fig. $8 \mathrm{C}$ vs. $8 \mathrm{D}$ ) was 269 significantly higher, when the inoculum was dislodged at day 27-29 compared to day 37-39 (Mann-Whitney 270 two-sample test (10), $p<0.0001)$. Furthermore, the number of reattached spores and seedlings on ropes 271 exposed to different agitation periods (Day 0-2 vs. Day 10-12) was significantly different $(p<0.0001, p=$ 2720.0012 , respectively). After nursing these ropes for additional seven days (counting day 10 ), the effect of 273 agitation period on the density of spores and seedlings remained significant $(p=0.0002, p=0.0009)$. In 274 contrast, the effect of inoculum age at dislodgement was insignificant on the spore density $(p=0.0697)$ and 275 seedling density $(p=0.9938)$. 


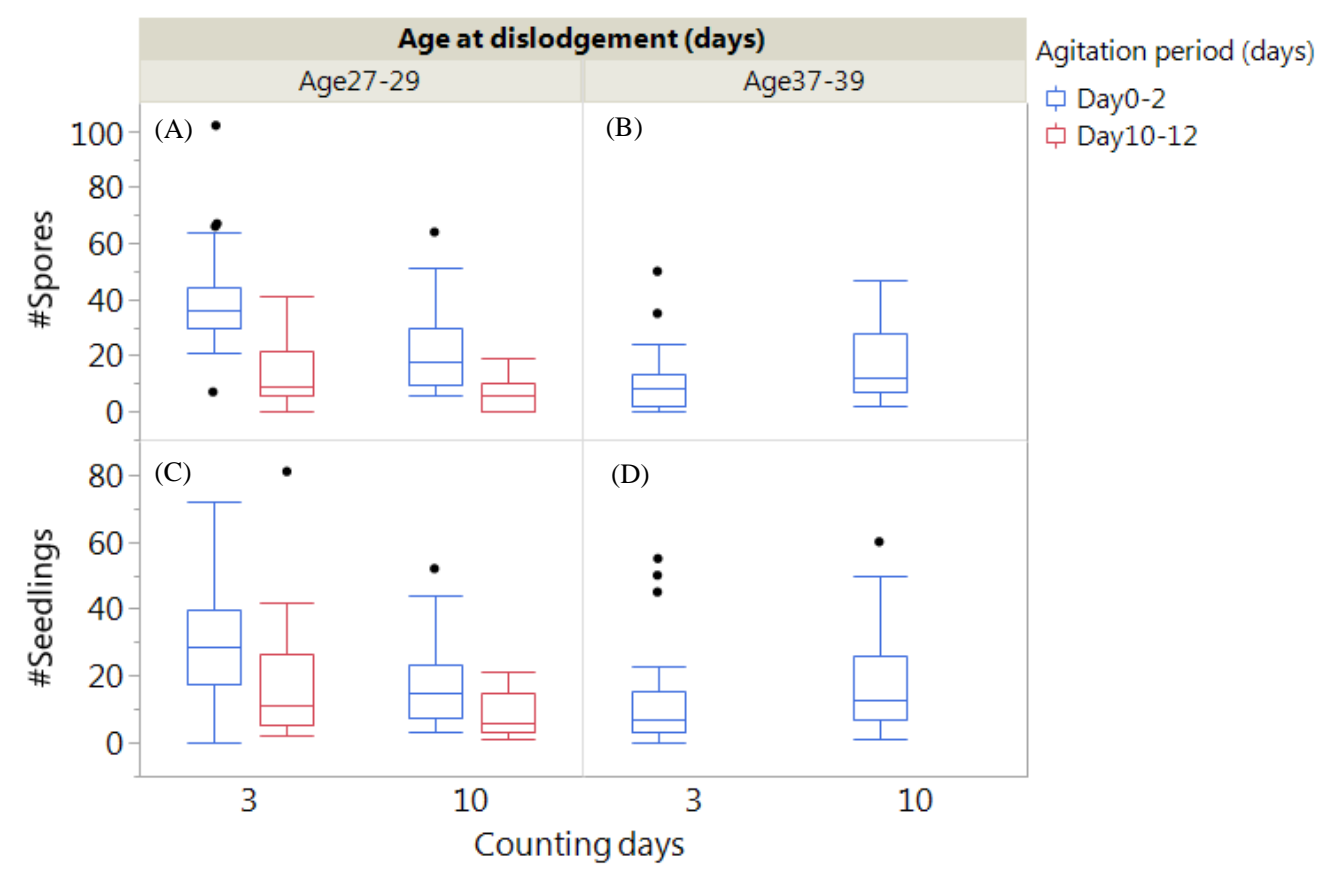

Figure 8.

3.3 Experiment 3: Including fertilization in hatchery

278 After 19 days in petri dish culture, the adjusted seedling number was $50.25 \%$ higher (fig. 9A) with male 279 gametes solution added, compared to the control (two-tailed Student's t test: $t(10), p<0.0001$ ), whereas no 280 significant differences were found at the other days $(p>0.98)$, except day 3 , where the control group showed 281 a slightly higher number of seedlings $(p=0.0042)$.

282 The effect of adding male gametes to the rope cultures (fig. 9B) was significant from day 3 (MANOVA: $F_{1,19}=$ $283121.445, p<0.0001)$ with higher number of seedlings at all counting days (253.2 \% at day 12$)$. Yet, the effect 284 of time was insignificant on the number of seedlings (MANOVA: $F_{3,17}=0.5462, p=0.6573$ ), but caused a 285 significant interaction term of gamete addition * time: $\mathrm{F}_{3,17}=4.0842, p=0.0235$, because of the higher 286 seedling count after day 0. 

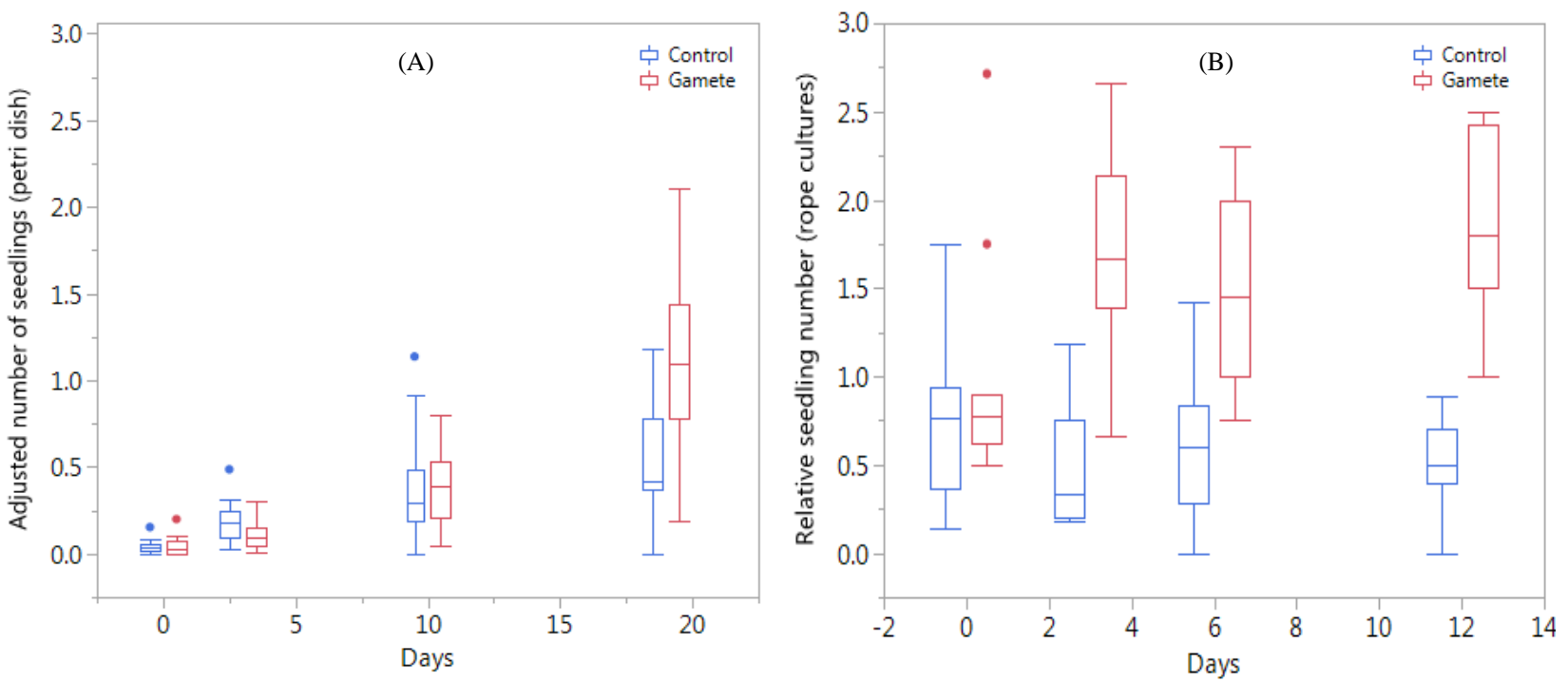

Figure 9.

\section{Discussion}

The results of this study demonstrate effective methods and strategies in the pursuit of optimizing the hatchery production of $P$. palmata by using vertical seeding tanks, consecutive use of sori packages and agitation during the seeding phase. The strategy of using a secondary seeding inoculum of germinated propagules, based on collecting the effluent spores, obviously increase the spore use efficiency. With presented seeding system, 9 nets were spore-seeded, with an equivalent linear length of $\sim 126$ meter of rope, using as little as $5 \mathrm{~g} \mathrm{FW}$ sori, which result in an average of 9 seedling $\mathrm{cm}^{-1}$ after 32 days. The use of spores for seeding substrates is prospective for larger scale cultivation (Browne 2001; Edwards 2007; Werner and Dring 2011). The latter argued that an initial seeding density of 100 spores $\mathrm{cm}^{-1}$ is required to obtain a final seedling density of $\sim 6-8$ seedlings $\mathrm{cm}^{-1}$ as a mortality rate of spores of $60-80 \%$ took place. On top, only male gametophytes developed a thallus, representing $50 \%$ of the total amount of spores. The initial spore density encountered in the present study (Exp. 1) on the nets was lower than 100 spores $\mathrm{cm}^{-1}$, however, we estimated a spore germination success (reciprocal to mortality) of $50-80 \%$ on the nets similar to what was achieved in a previous study (Le Gall et al., 2004). This indicates that the seeding and nursery conditions presented here were good, though it might be overestimated, as we were not able to count the dying spores. In contrast, we observed a germination success of only 8-14 \% in petri dishes cultured in stagnant seawater under the same conditions (unpublished work), which is in the range of previous report (Edwards 2007; Edwards and Dring 2011). By using higher amounts of sori in the seeding phase of net, the nets showed higher spore density after 3 days, but decreased to similar levels for all sori amount used, after 32 days of nursery, in line with previous findings (Edwards 2007; Werner and Dring 2011). In present study, the average seedling density after 32 days of nursery was not significantly affected by the sori amounts tested. Besides testing efficient ways to handle sori tissue for optimal spore yield, it is important that future hatchery trials consider the sori-to-substrate density, as high spore density seem to even out during nursery, thus the sori could have been used more efficient. A current hatchery protocol for $P$. palmata, found that a sori-to-substrate ratio of $150 \mathrm{~g} \mathrm{FW}$ sori $84 \mathrm{~m}^{-1}$ substrate was required to secure sufficient seedling density, 
which converts to $130 \mathrm{~kg} \mathrm{FW}$ fronds to seed one long-line of $100 \mathrm{~m}$ (Werner and Dring 2011). In comparison, several kilometers of substrate can be seeded with motile zoospores of Saccharina latissima by using $150 \mathrm{~g}$ sori, due to the multifold number of biflagellate zoospores released within 1 hour and their capability of high dispersal (personal observation). We suggest that a lower amount of sori is sufficient for seeding, while considering the sori-to-substrate ratio.

Three times the amount of seeded substrate was produced by using three consecutive seeding periods, compared to the conventional 3-days seeding phase. The highest seedling density after 32 days for nets seeding was found in the second ( $\sim 8$ seedlings $\mathrm{cm}^{-1}$ and third seeing period $\left(\sim 10\right.$ seedlings $\mathrm{cm}^{-}$ $\left.{ }^{1}\right)$. In the first seeding period (Day 0-3), our tank setup provided a spore-seeding efficiency of $16 \%$, meaning that $\sim 84 \%$ of the released tetraspores were detained in the down-stream detaining tanks. The amount of detained spores was highest after the second seeding period (Day 3-6). Even 38 days after finalizing the last seeding period we observed red tetraspore aggregates in some of the spore-detaining tanks. This observation supports previous findings, where sori was observed to release for 21 days (Schmedes et al. 2019) to 40 days (Wood 2018).

Several bottlenecks have been identified by using the current hatchery protocol for P. palmata for large-scale cultivation - a protocol where sori is placed above the cultivation substrates (1:1 areal coverage) in horizontal tanks, which impose a high sori requirement. Facing other challenges when hatching rhodophytes, such as seasonal variation in spore availability (Kain 1986; Le Gall et al. 2004), a relative low spore release yield (Edwards 2007), poor spore dispersal before settlement (Edwards and Dring 2011) and low survival of spores (Sanderson 2006; Werner and Dring 2011), all impose a low spore use efficiency and little control of seedling quality. Overall, an even spore dispersal and good seedling density was found in this study using a flow-through system and relative high aeration, agitating the water. Nevertheless, further investigations of the previous mentioned challenges are highly relevant to optimize before commercial hatcheries can be established. Hence, the recently developed GMA-method (Schmedes et al. 2019) to improve the spore efficiency for hatching $P$. palmata was investigated. This method was applied by dislodging and maceration of detained spores, which then germinated into propagules, which again were macerated to break aggregates of spores and tiny seedlings into single and small groups of spores and seedlings, before used as a secondary seeding inoculum. The level of water agitation of $2.5 \mathrm{~L} \mathrm{~min}^{-1}$ dispersed the propagules, yet, did not compromise the establishment of a discoid reattachment on the ropes (Exp. 2). Results demonstrated that the reattachment was negatively affected by the biological age at dislodgement and amount of days in agitation, which adds knowledge to the extent of which macerated $P$. palmata propagules can be used as seeding inoculum. This is in agreement with findings in other red seaweed species, such as Chondracanthus chamissoi (Gigartinales), which forms a substrate reattachment by the production of secondary attachment discs (Sáez et al. 2008). The thallus fragments showed a decreasing reattachment probability over time (Fonck et al. 2008). Also, the red seaweed Gelidium chilense (Montagne) formed bundles of rhizoids in agitated water (Santelices and Varela 1994), while absent in Gelidium coulteri cultured in stagnant water conditions (Macler and West 1987). In comparison, a direct seeding method for cultivating the brown macroalgae species $S$. latissima, as a way to optimize hatchery duration and costs, is currently used by the Hortimare company, as a seeding technique for commercial 
cultivation in Europe. Here, tiny germinated and activated sporophytes are applied to substrates and establish firm attachment with their developing haptera organs, with a potential benefit of using a glue (Kerrison et al. 2018). Whether the propagule seeding method of P. palmata would benefit by using glue as a means to maximize seedling density, is of high interest due to the high commercial value of the biomass.

The inclusion of a fertilization step proved to be highly relevant to increase the number of seedlings in the hatchery production, by releasing male gametes and adding this male gamete solution to the female gametophytes that are developing their trichogynes (Mine and Tatewaki 1994; Le Gall et al. 2004). This resulted in at least a doubling of the number of seedlings on spore-seeded rope and suggests that male gametes can be added 10-22 days after seeding substrates to increase the overall spore-use-efficiency of $P$. palmata.

\section{Conclusions}

A new method is reported here to handle fertile sori of $P$. palmata for efficient release and dispersal of tetraspores using sori packages in vertical flow-through tanks. This achieves a sufficient seedling density $\sim 9$ seedlings $\mathrm{cm}^{-1}$ rope. Consecutive use of sori greatly improves the spore use efficiency and was found to have a positive effect on seeding quality, even for different sori amounts used in the sporulation phase. The spore inoculation success (net-seeding efficiency $\sim 16 \%$ ) was relative low, however, the $\sim 84 \%$ effluent spores was used in propagule inoculation by using the GMA-method. Hence, to increase the use of spores for efficient inoculation, the importance of addressing following parameters to further improve the spore-use efficiency for seeding P. palmata is needed. The following are of importance, i.e., tank typology, water motion for optimal spore dispersal and settlement, intermittent batch conditions to increase net seeding efficiency, substrate-to-volume density, sori position, and flow-through rate. It was demonstrated that effluent spores from the SDTs were suited as a secondary seeding inoculum, using the Germinate-Macerate-Agitate seeding method (Schmedes et al. 2019). 
References

Admassu H, Gasmalla MAA, Yang R, Zhao W (2018) Bioactive peptides derived from seaweed protein and their health benefits : Antihypertensive, antioxidant, and antidiabetic properties. J Food Sci 83(1).

Browne KL (2001) Mariculture of the edible red alga, Palmaria palmata. PhD thesis, Queen's University of Belfast.

Corey P, Kim JK, Duston J, Garbary DJ (2014) Growth and nutrient uptake by Palmaria palmata integrated with Atlantic halibut in a land-based aquaculture system. Algae 29(1):35-45.

Edwards MD (2007) The cultivation of the edible red alga, Palmaria palmata for aquaculture, PhD thesis, The Queen's University of Belfast.

Edwards MD, Dring MJ (2011) Open-Sea cultivation trial of the red alga, Palmaria palmata from seeded tetraspores in Strangford Lough, Northern Ireland. Aquaculture 317(1-4):203-209.

Fonck E, Martínez R, Vásquez J, Bulboa C (2008) Factors that affect the re-Attachment of Chondracanthus chamissoi (Rhodophyta, Gigartinales) thalli. J Appl Phycol 20(3):311-14.

Grandorf Bak U (2019) Seaweed cultivation in the Faroe Islands : An investigation of the biochemical composition of selected macroalgal species, optimised seeding technics, and open-ocean cultivation methods from a commercial perspective. PhD thesis, Technical University of Denmark.

Guillard RRL and Ryther JH (1962) Studies on Marine Planktonic Diatoms I. Cyclotella nana Hustedt and Detonula confervacea (Cleve) Gran. Can J Microbiol 8:229-239.

https://doi.org/10.1139/m62-029

Harnedy PA, Soler-Vila A, Edwards MD, FitzGerald RJ (2014). The effect of time and origin of harvest on the in vitro biological activity of Palmaria palmata protein hydrolysates. Food Res Int 62:746-52.

Kain JM (1986) Plant size and reproductive phenology of six species of Rhodophyta in subtidal Isle of Man. Br. Phycol J 21(2):129-38.

Kerrison PD, Stanley MS, Hughes AD (2018) Textile substrate seeding of Saccharina latissima sporophytes using a binder: An effective method for the aquaculture of kelp. Algal Res 33:352-57.

Lee D, Mizuho N, Yutaka S, Hiroki S (2017) Anti-inflammatory effects of dulse (Palmaria palmata) resulting from the simultaneous water-extraction of phycobiliproteins and chlorophyll a. Food Res Int 100:51421.

Le Gall L, Pien S, Rusig AM (2004) Cultivation of Palmaria palmata (Palmariales, Rhodophyta) from isolated spores in semi-controlled conditions. Aquaculture 229(1-4):181-91.

Macler BA, West JA (1987) Life history and physiology of the red alga, Gelidium coulteri, in unialgal culture. Aquaculture 61(3-4):281-93. 
Matos J, Costa S, Rodrigues A, Pereira R, Pinto IS (2006) Experimental integrated aquaculture of fish and red seaweeds in Northen Portugal. Aquaculture 252(1):31-42..

Mine I, Tatewaki M (1994) Attachment and fusion of gametes during fertilization of Palmaria sp. (Rhodophyta). J Phycol 30:55-66.

Morgan KC, Simpson FJ (1981) The cultivation of Palmaria palmata: Effect of light intensity and temperature on growth and chemical composition. Bot Mar 24(10):547-52.

Mouritsen OG, Dawczynski C, Duelund L, Jahreis G, Vetter W, Schröder M (2013) On the human consumption of the red seaweed dulse (Palmaria palmata (L.) Weber \& Mohr). J Appl Phycol 25(6):1777-91.

Pang S, Lüning K (2004) Tank cultivation of the red alga Palmaria palmata: Effects of intermittent light on growth rate, yield and growth kinetics. J Appl Phycol 16(2):93-99.

Sáez F, Macchiavello J, Fonck E, Bulboa C (2008) The role of the secondary attachment disc in the vegetative propagation of Chondracanthus chamissoi (Gigartinales; Rhodophyta). Aquat Bot 89 (1):6365.

Sanderson JC, Dring MJ, Davidson K, Kelly MS (2012) Culture, yield and bioremediation potential of Palmaria palmata (Linnaeus) Weber \& Mohr and Saccharina latissima (Linnaeus) C.E. Lane, C. Mayes, Druehl \& G.W. Saunders adjacent to fish farm cages in Northwest Scotland. Aquaculture 354355:128-135.

Sanderson JC (2006) Reducing the environmental impact of sea-cage fish farming through cultivation of seaweed. PhD thesis, UHI Millenium Institute \& Scottish Association of Marine Science (SAMS)

Santelices B, Varela D (1994) Abiotic control of reattachment in Gelidium chilense (Montagne) Santelices \& Montalva (Gelidiales; Rhodophyta). J Exp Mar Biol Ecol 177:145-55.

Schiener P, Zhao S, Theodoridou K, Carey M, Mooney-McAuley K, Greenwell C (2017) The nutritional aspects of biorefined Saccharina latissima, Ascophyllum nodosum and Palmaria palmata. Biomass Conversion and Biorefinery 7(2):221-35.

Schmedes PS, Nielsen MM, Petersen JK (2019) Improved Palmaria palmata hatchery methods for tetraspore release, even settlement and high seedling survival using strong water agitation and macerated propagules. Algal Res 40. doi: 10.1016/j.algal.2019.101494

van der Meer JP, Chen LCM (1979) Evidence for sexual reproduction in the red algae Palmaria palmata and Halosaccion ramentaceum. Can J Bot 57(21):2452-59.

van der Meer JP, Todd ER (1980) The life history of Palmaria palmata in culture. A new type for the Rhodophyta. Can J Bot 58:1250-56.

Werner A, Dring MJ (2011) Aquculture explained: Cultivating Palmaria palmata. Irish Sea Fisheries Board, 
444 Wood E (2018) Cultivation of Palmaria palmata: spore release, vegetative propagation and decontamination 445 techniques. Scottish Associaiton for Marine Science (SAMS) and University of the Highlands and Islands.

447 Acknowledgements

448 We sincerely thank Pascal David Alain Barreau and Kasper Lenda Andersen for their technical help installing 449 the experimental setup, as well as for system maintenance and data collection. The study was funded by the 450 Joint Doctoral Degree agreement between the National Institute of Aquatic Resources (DTU Aqua) at 451 Technical University of Denmark and the Norwegian University of Science and Technology (NTNU), Norway, 452 as well as the Tang.nu project (under Grant Agreement No. 13744, Velux Foundation) and the MacroSea 453 project, Grant no. 254883, funded by the Research Council of Norway.

454 Compliance with Ethical Standards

455 Informed consent of the document with no conflict of interest. We did not conduct research on human or 456 animals. 
Figure 1. A: Parallel flow-through setup of conical seeding tanks $(30 \mathrm{~L})$ used for experiment 1. B: The sori packages were fixed centrally above the net spirals and $2 \mathrm{~cm}$ below water surface. Effluent spores were detained in spore-detaining tanks (SDTs). C: Aeration (1.2 $\left.\mathrm{L} \mathrm{min}^{-1}\right)$ from the bottom provided hemispherical water circulation and dispersal of released spores.

Figure 2. A: Fertile tetrasporophytic fronds were cleaned and the presence of dark-red sporangia were validated (B). C: Sori packages (5, 10, or $15 \mathrm{~g} \mathrm{FW)} \mathrm{were} \mathrm{prepared} \mathrm{by} \mathrm{placing} \mathrm{the} \mathrm{sori} \mathrm{between} \mathrm{two} \mathrm{layers} \mathrm{of}$ green plastic mesh $(n=3)$.

Figure 3. A: Dark-red aggregates of spores on the bottom of spore-detaining tanks (STDs) accumulated during sporulation. B: A well-mixed spore solution was obtained by dislodging the aggregates and macerating them. C: The number spores were counted in five random fields (each of $0.0035 \mathrm{~mm}^{2}$ ) and used as a basis to estimate the total amount of detained spores.

Figure 4. A: Detained and macerated spores of $P$. palmata at the bottom of a $5 \mathrm{~L}$ Plexiglas tank. B: Plexiglas tank after dislodgement of propagules on the left side of the tank. C: Propagule mix after dislodgement and maceration. The solution was inspected before $(D)$ and after $(E)$ the maceration treatment. F: Single individual seedling displaying hair-like proliferations from the basal disc area. Scale bar represent $500 \mu \mathrm{m}$.

Figure 5. A: Fertile male gametophytes inspected by stereomicroscopy. B: cross-section microscopy was used to verify reproductive appearance of the males. C, D: Spherical male gamete released in a solution.

Figure 6. The number of spores (A-C) and seedlings (D-F) attached to the nets and the spore germination percentage (G-I). $4 \mathrm{~cm}$ net pieces were counted on day 3, 19 and 32 after each of the three consecutive periods (Day 0-3, Day 3-6, Day 6-9) with the use of different sori amount $(5,10,15 \mathrm{~g})$. Data is presented as mean $\pm S E, n=3$.

Figure 7. A-I: The extrapolated number of spores attached to the nets and (D-F) the total number of detained spores collected in the spore-detaining tanks (SDTs) as a function of three consecutive seeding periods and the use of three different amount of sori (5, 10, $15 \mathrm{~g} \mathrm{FW).} \mathrm{G-I:} \mathrm{Net} \mathrm{seeding} \mathrm{efficiency,} \mathrm{calculated} \mathrm{from}$ equation 1. Data is presented as mean $\pm S E, n=3$.

Figure 8. Attached spores (A-B) and seedlings (C-D) on rope pieces seeded with macerated propagule solution at day 3 and 10 and as a function of age at dislodgement (day 27-29 vs. day 37-39) and agitation period (day 0-2 vs. day 10-12). Data is presented as outlier box plots ( $1^{\text {st }}, 3^{\text {rd }}$ quartile whisker) based on three subpart counts on each of ten pieces of rope $(n=10, N=30)$.

Figure 9. A: The normalized seedling count in petri dish cultures $(n=10)$ of macerated $P$. palmata propagules as an effect of adding male gametes. B: The normalized seedling count on spore-seeded rope cultures $(n=11)$ as an effect of adding male gametes. Data is presented as outlier box plots (1st, $3^{\text {rd }}$ quartile whisker). 